\title{
Percepções dos estudantes do curso de Farmácia da Universidade Federal de Alagoas na disciplina Botânica aplicada à farmácia e seu conhecimento sobre plantas medicinais
}

\section{Perceptions of the students of the Pharmacy graduation course of the Universidade Federal de Alagoas in the discipline botany applied to pharmacy and their knowledge about medicinal plants}

\author{
${ }^{1}$ Leomar da Silva de Lima leomar.dasilvalima@gmail.com \\ ${ }^{2}$ Gabriela Santos da Silva \\ ${ }^{1}$ Graziela Cury
}

\section{RESUMO}

\begin{abstract}
A importância das plantas utilizadas como medicinais, desde aproximadamente 5000 a.C., bem como sua relevância como base para ciências Médicas e Farmacêuticas são fatos indiscutíveis. Até hoje, as plantas medicinais são utilizadas, de forma precária em comunidades carentes, mas também já são processadas pelas grandes indústrias farmacêuticas. Mediante a importância das plantas para a produção de fármacos, a grade de disciplinas do curso de Farmácia da UFAL, tem como disciplina obrigatória Botânica Aplicada à Farmácia. No entanto, já é observado, há algum tempo, certa falta de interesse dos alunos na disciplina. Com o intuito de compreender o real motivo do desinteresse dos estudantes, este trabalho realizou uma análise da relação dos discentes com o tema, para investigar o conhecimento dos graduandos a respeito das plantas medicinais e propor uma mudança na ementa da disciplina, e despertar um maior interesse por parte desses estudantes. Através da utilização de dois questionários entregues aos estudantes, foi possível coletar os dados necessários. Os resultados apresentaram diferentes opiniões dos discentes, as quais variaram desde os que consideram a disciplina interessante e importante para o curso, até os que sugeriram que a disciplina seja retirada da grade curricular. Com os dados obtidos foi possível compreender melhor a relação dos alunos com a disciplina e traçar métodos que possam deixá-la mais interessante.
\end{abstract}

Palavras-chave: Ensino, Fármacos, Fitoterapia, UFAL.

\section{ABSTRACT}

The importance of the medicinal plants since approximately 5000 b.C., as well as their relevance to Medical and Pharmaceutical Sciences constitute undeniable facts in the specialized literature. Nowadays, they are used more precariously in needy communities, but they have also been processed by the major pharmaceutical industries for the production of drugs. Given this, the Pharmacy Graduation Course of the UFAL has as compulsory discipline Botany Applied to Pharmacy. However, it is already observed, over a period

1 Universidade Federal de Alagoas

2 Escola Superior de Agricultura Luiz de Queiroz 
of time, a disinterest in the discipline. This paper aims to understand the real reason of this indifference, for this, this work performed an analysis of the relation of the students with the theme, to investigate their knowledge about medicinal plants and to construct a proposal of change in the discipline syllabus, arousing interest in the students. For the data collect, two questionnaires were prepared previously and then distributed to the students. The results showed different opinions of the students, which ranged from those who consider the discipline interesting and those who suggested its withdrawal of the curriculum. With the obtained data it was possible to improve the understanding about the relation of the students with the discipline and outline methods to become it more interesting.

Keywords: Drugs, Phitotherapy, Teaching, UFAL.

\section{INTRODUÇÃO}

A utilização de plantas medicinais é praticada desde os primórdios da civilização humana. Na pré-história, o ser humano procurava amenizar suas dores ou tratar suas moléstias através da ação dos princípios ativos existentes nos vegetais, embora de modo totalmente empírico ou intuitivo baseado em descobertas ao acaso (VAN DEN BERG, 1987).

O uso das plantas pela humanidade ao longo de sua história e o conhecimento que foi desenvolvido e passado são as bases da Medicina, da Farmácia e de outras áreas da ciência. As drogas farmacêuticas hoje bastante difundidas são fruto desse conhecimento, e apesar do advento de substâncias sintéticas, as plantas continuam sendo as precursoras de vários medicamentos. Porém o uso direto das plantas pela população continua e esse conhecimento se difunde cada vez mais.

Segundo Lorenzi e Matos (2002) e Silva (2013), até hoje em várias regiões carentes e, mesmo em grandes cidades do mundo, plantas medicinais são comercializadas em feiras livres, mercados, casas, ervanárias, e cultivadas em quintais residenciais. Os relatos e observações populares das plantas medicinais contribuem significativamente para a divulgação terapêutica dos vegetais, que normalmente são empiricamente indicadas, embora de muitas destas plantas ainda se desconheçam os constituintes químicos responsáveis por seus efeitos terapêuticos. No entanto, os usuários de plantas medicinais de todo o mundo mantêm o consumo destas, consagrando as informações de pesquisadores em estudos multidisciplinares para o enriquecimento dos conhecimentos sobre a inesgotável fonte medicinal natural. Como exemplo, podemos citar estudos recentes que relatam a análise de plantas com potencial medicinal (BARROS et al., 2016; CAVALCANTI-DANTAS et al., 2016; FENALTI et al., 2016; MATTA et al., 2016; SANTOS et al., 2016).

Vale ressaltar ainda que os estudos em plantas medicinais devem seguir um criterioso rigor científico, para a liberação da produção de fitoterápicos (BRITO e RODRIGUES, 2015), o que só pode ser obtido, pela atuação de profissionais da área.

O uso terapêutico das plantas medicinais é tão importante atualmente, sendo seus compostos químicos cientificamente investigados que, de modo geral, nas Universidades os cursos de Farmácia têm como disciplina obrigatória a Botânica, tendo inclusive quem considere a Botânica como uma diretriz nos cursos de Fitoterapia para profissionais da saúde (NOGUEIRA et al., 2013).

Na Universidade Federal de Alagoas - UFAL, o curso de Farmácia tem uma carga horária de 5.000 horas distribuídas em 10 períodos. Na grade curricular do curso há oficialmente duas disciplinas que trazem a temática botânica, plantas medicinais e fitoterapia, são elas: FARM028 - Botânica Aplicada à Farmácia, disciplina obrigatória, abordada no quarto período com carga horária de 60 horas e FARM026 - Fitoterapia, disciplina eletiva, com carga horária de 40 horas. 
Em relação à disciplina Botânica Aplicada à Farmácia, de acordo com a sua ementa, as propostas de suas aulas estão principalmente relacionadas com temas básicos da Botânica, como Morfologia e Sistemática Vegetal (CCGF - UFAL).

Apesar da importância da Botânica para o curso de Farmácia, relatos feitos por professores e monitores da disciplina ao longo de algum tempo, têm revelado certo desinteresse dos estudantes pelos assuntos abordados em aula, o que gera frustração e desmotivação, com consequente queda de desempenho da parte do professor em relação à disciplina.

O real motivo a respeito dessa "falta" de interesse pela disciplina nunca foi bem compreendido por parte dos professores, mas é sempre notado nas turmas que a cursam, trazendo, assim, debates entre os docentes da Botânica e alguns alunos que com eles trabalham. Faz-se então necessário analisar o porquê desse fato e como resolvê-lo. Estudos que já abordaram esta questão, um em relação à disciplina de Homeopatia no curso de Farmácia (CORRÊA et al., 2015) e outro realizado em cursos de áreas distintas (NÓBREGA et al., 2017), apresentaram resultados positivos para o curso e também forneceram dados para aperfeiçoamentos da grade curricular. Também há na literatura ocorrência de trabalhos realizados até mesmo no Ensino Médio, como apontado por Ferreira et al. (2015) e Souza et al. (2015).

Diante dessa problemática, este trabalho propôs realizar uma análise da relação dos discentes com o tema para compreender os motivos pelos quais existe esse suposto desinteresse previamente observado. Assim, será possível sugerir mudanças na ementa da disciplina, objetivando despertar um maior interesse por parte desses estudantes. Além disso, este trabalho também teve o objetivo de investigar o conhecimento dos graduandos a respeito das plantas medicinais, uma vez que o conhecimento e uso das plantas pela humanidade são as bases de seu curso.

\section{PROCEDIMENTOS METODOLÓGICOS}

Foram utilizados questionários previamente estruturados e aplicados da mesma forma com todos participantes da pesquisa. O questionário 1 (destinado aos estudantes do $1^{\circ}$ ao $4^{\circ}$ período) e o questionário 2 (direcionado a estudantes do $5^{\circ}$ ao $10^{\circ}$ período). O questionário 2 difere por conter perguntas a respeito de, possível, desinteresse à disciplina após seu curso e sugestões de mudanças para a mesma.

Foram disponibilizados 15 questionários por turma, nove turmas no total $\left(1^{\mathrm{a}}\right.$ ao $9^{\circ}$ período), totalizando 135 questionários. Por se tratar de uma turma de concluintes não houve a participação do $10^{\circ}$ período nessa pesquisa, uma vez que a mesma realiza estágios fora da universidade. A distribuição dos questionários se deu em visitas às turmas, onde, após a explicação do caráter da pesquisa, a leitura do Termo de Compromisso Livre e Esclarecido (TCLE) e a resposta positiva sobre a participação os questionários foram distribuídos. O Comitê de Ética em Pesquisa (CEP) concedeu parecer positivo à realização desse trabalho, processo $n^{\circ}$ 54685316.3.0000.5013, no dia 28/04/2016. A pesquisa foi realizada entre os meses de julho e agosto do referido ano.

Das plantas citadas, a maioria foi apontada por seu nome popular (ex.: juá, camomila, abacaxi, romã, etc.), porém, se tratando de nomes populares consagrados pelo seu uso indicamos tais plantas pelo seu nível de espécie, através da mesma bibliografia utilizada na classificação taxonômica das plantas que foram apontadas com seu nome científico (ex.: Mentha x piperita L.; Digitalis lanata Ehrh). 


\section{RESULTADOS E DISCUSSÃO}

Apenas estudantes do $1^{\circ}$ ao $8^{\circ}$ período devolveram os questionários, totalizando 40 amostras, representando apenas $2,96 \%$ do total de questionários aplicados. Desse, o questionário 1 foi aplicado em 25 alunos e o questionário 2 em 15.

Das/dos estudantes que participaram da pesquisa: 26 são mulheres e 14 são homens, possuindo de 17 a 35 anos de idade. Esses estudantes são oriundos de cinco estados: Alagoas (30); Pernambuco (seis); Bahia (dois); Paraíba (um) e Santa Catarina (um). Em relação às/aos estudantes de Alagoas: 14 são da capital (Maceió) e 16 têm como local de origem municípios do interior.

\section{1 ANALISE DO QUESTIONÁRIO 1}

Em relação aos dados referentes ao questionário 1 , foram coletados três questionários no $1^{\circ}$ período, cujos resultados revelaram que: os motivos que os levaram a cursar Farmácia foi o interesse pela área e o mercado de trabalho. Consideram a disciplina importante por ser base do curso e possibilitar a descoberta de novos fármacos. Os três relataram ter interesse em plantas medicinais e citaram um total de 23 plantas. Dois citaram 10 aplicações para as plantas: ansiedade, depressão, tensão muscular, cicatrização, náuseas, vômitos, repelente natural, desintoxicação, anti-inflamatório e descongestionante das vias respiratórias. Sobre preparos oriundos das plantas: três citaram o chá e lambedor, um citou extrato e um citou o floral. Os três responderam que fazem/fizeram uso de plantas em algum tratamento e citaram um total de 11 plantas utilizadas.

No $2^{\circ}$ período totalizou-se seis estudantes. O interesse na área da saúde foi o motivo que as/os levaram a cursar Farmácia. Cinco julgaram a disciplina importante, pois através da mesma é possível descobrir novos fármacos, e também pela possibilidade de enriquecer o conhecimento e compreender melhor o assunto. Todos se mostraram interessados em plantas medicinais e citaram um total de 10 plantas, contudo duas pessoas não responderam essa questão. Duas pessoas citaram quatro aplicações: febre, problemas intestinais, dores e relaxante. Sobre preparos oriundos das plantas todos citaram chá e lambedor. Cinco responderam que fazem/fizeram uso de plantas em algum tratamento e quatro estudantes citaram um total de quatro plantas utilizadas.

Dos questionários coletados no $3^{\circ}$ período, nove estudantes fornecerem os questionários preenchidos. Afinidade com o curso e com a área de atuação os levaram a escolher Farmácia. Todos acham importante haver a disciplina na grade curricular, pois através da mesma é possível haver um tratamento diferenciado ao paciente, possibilita a descoberta de novos fármacos, além de interesses financeiros e cosmetológicos. Todos revelaram interesse por plantas medicinais e citaram um total de 13 plantas, contudo três pessoas não responderam essa questão. Cinco pessoas citaram oito aplicações: calmante, dores musculares, diurético, problemas no fígado, gripe, artrite, problemas estomacais e enjoo. A respeito de preparos oriundos das plantas, oito citaram chá, sete citaram lambedor e três citaram extrato. Sete responderam que fazem/fizeram uso de plantas em algum tratamento e as mesmas citaram um total de seis plantas utilizadas.

Dos questionários coletados no $4^{\circ}$ período, sete estudantes participaram do trabalho. Afinidade com o curso e a área de atuação e o mercado de trabalho foram os motivos que os levaram a cursar Farmácia. Todos acham importante haver a disciplina na grade curricular, pois através da mesma é possível a descoberta de novos fármacos e enriquecer o conhecimento. Todos se interessam por plantas medicinais, citando um total de nove plantas. Três pessoas apontaram quatro aplicações: dor de barriga; calmante; inflamação e dor de cabeça. Sobre preparos oriundos das plantas, todas/os citaram chá e lambedor e dois citaram extrato. Quatro responderam que fazem/fizeram uso de plantas em algum tratamento e as mesmas citaram um total de seis plantas utilizadas.

No total, os estudantes do $1^{\circ}$ ao $4^{\circ}$ período, citaram 34 espécies botânicas. 


\section{2 ANALISE DO QUESTIONÁRIO 2}

Em relação aos dados referentes ao questionário 2, sete estudantes do $5^{\circ}$ período entregaram as respostas. Afinidade com o curso e com a área de atuação; o mercado de trabalho e a nota atingida no Exame Nacional do Ensino Médio (ENEM) foram os motivos que os levaram a cursar Farmácia. Todos consideram a disciplina importante, pois através da mesma é possível a descoberta de novos fármacos, aprimorar o conhecimento sobre plantas medicinais e por ser uma nova alternativa de tratamento. Quando questionados se houve mudanças no que pensam a respeito da disciplina após sua conclusão, seis responderam que sim, pois a mesma contribuiu para um maior conhecimento sobre as plantas: quais partes são usadas e seus princípios ativos, e seu valor para a indústria farmacêutica, porém, um respondeu que não, pois já havia um interesse pela temática. Foi pontuado que a disciplina poderia dar uma maior ênfase na área farmacêutica e na aplicação das plantas; focar na identificação das espécies para evitar erros graves que possam gerar problemas e em seus constituintes ativos. Todos se interessam por plantas medicinais, citando um total de 18 plantas. Foram mencionadas nove aplicações: cicatrização, analgésico, anti-inflamatório, estresse, insônia, laxante, calmante, relaxante e dor de barriga. Sobre preparos oriundos das plantas, todas/os citaram chá, lambedor e extrato e um citou tintura, cataplasma e suco. Seis responderam que fazem/fizeram uso de plantas em algum tratamento e as mesmas citaram um total de 10 plantas utilizadas.

Dos questionários coletados do $6^{\circ}$ período, três estudantes revelaram que, afinidade com o curso e com a área de atuação, o mercado de trabalho e a nota atingida no Exame Nacional do Ensino Médio (ENEM) foram os motivos que os levaram a cursar Farmácia. Todos acham a disciplina importante, pois através da mesma é possível a descoberta de novos fármacos, pela Botânica ser a base para outras disciplinas e também por sua importância para a fitoterapia. Quando perguntados se houve mudanças a respeito do que pensam sobre a disciplina após sua conclusão, dois responderam de forma negativa, sendo que um já gostava da área, um não tem interesse na mesma e um respondeu positivamente, pois houve um aprofundamento dos conhecimentos. Sobre propostas de mudanças na disciplina foi pontuado que a disciplina fosse mais voltada para o uso das plantas na farmacologia e na área da saúde como uma introdução para a Farmacognosia, mas que nas aulas práticas pudessem ser analisados um maior número de plantas medicinais. Todos apresentaram interesse por plantas medicinais, citando um total de 11 plantas. Foram totalizados oito aplicações: calmante, infecção respiratória, secreção biliar, dores, enjoo, expectante, laxante e problemas intestinais. Sobre preparos oriundos das plantas, todas/os citaram chá, lambedor e extrato. Todos responderam que fazem/fizeram uso de plantas em algum tratamento e as mesmas citaram um total de quatro plantas utilizadas.

Do $7^{\circ}$ período foram coletados quatro questionários. Afinidade com o curso e com a área de atuação foram os motivos que os levaram a cursar Farmácia, sendo que um afirmou ter sido sua segunda opção. Três estudantes acham a disciplina necessária, pois consideram a fitoterapia importante, porém um estudante não a considera importante, pois não acha interessante conhecer as partes estruturais das plantas. Quando perguntados se houve mudanças a respeito da disciplina após sua conclusão, três responderam negativamente e um respondeu positivamente, mas ressalva que a mudança se deu após cursar a disciplina de Farmacognosia. Sobre propostas de mudanças na disciplina foi pontuado que a mesma fosse mais voltada para o curso e para a área farmacêutica e que houvesse mais aulas práticas para o corte de tecido vegetal e preparação de lâminas. Uma pessoa ainda sugeriu retirar a disciplina da grade curricular do curso. Três estudantes revelaram interesse por plantas medicinais, sendo que dois citaram um total de sete plantas. Um estudante citou duas aplicações: antifúngica e anti-hipertensiva. Sobre preparos oriundos das plantas, quatro citaram chá e lambedor, três citaram extrato e um citou tintura; pó; soluções hidro alcoólica e garrafada. Três responderam que fazem/fizeram uso de plantas em algum tratamento e as mesmas citaram um total de seis plantas utilizadas.

Dos questionários entregues ao $8^{\circ}$ período, apenas um estudante retornou as informações. Afinidade com o curso e com a área de atuação levou-lhe a cursar Farmácia. Acredita na importância da disciplina na grade curricular, pois através da mesma é possível a descoberta de novos fármacos. Quando perguntado se houve mudanças a respeito da disciplina após sua conclusão, respondeu de forma positiva, pois pode compreender melhor 
a importância da fitoterapia. Sobre propostas de mudanças na disciplina foi pontuado que a mesma fosse mais voltada para o curso e para a área farmacêutica. Interessa-se por plantas medicinais e citou um total de cinco plantas. Mencionou duas aplicações: dor de barriga e cicatrização. Sobre preparos oriundos das plantas foram citados chá, lambedor e extrato. Faz/fez uso de plantas em algum tratamento e a mesma citou uma planta utilizada.

No total, os estudantes do $5^{\circ}$ ao $8^{\circ}$ período, citaram 28 espécies botânicas.

\subsection{DAS PLANTAS CITADAS}

Referente ao conhecimento de plantas medicinais, os estudantes que participaram dessa pesquisa, citaram um total de 48 plantas: "Agrião”. Amaryllidaceae - Allium sativum L. Amaranthaceae - Chenopodium ambrosioides L. Anacardiaceae - “Aroeira”. Apiaceae - Coriandrum sativum L. Asphodelaceae - Aloe vera (L.) Burm. f. Asteraceae - "Arnica”; Baccharis sp. e Chamomilla recutita (L.) Rauschert ."Boldo”. Bromeliaceae - Ananas comosus (L.) Merr. Cannabaceae - Cannabis sativa L. Caprifoliaceae - Valeriana officinalis L. "Cidreira”. "Erva doce”. Euphorbiaceae - Jatropha multifida L. "Espinheira santa”. Fabaceae - "Angico”; "barbatimão”; "mulungú”; Glycine $\max$ (L.) Merr. e "sucupira”. Gentianaceae - "Genciana”. Lamiaceae - "Alfavaca”; Melissa officinalis L.; Mentha x piperita L.; "Hortelã”; "Hortelã grossa” e Rosmarinus officinalis L. Lauraceae - "Canela”. Lythraceae - Punica granatum L. Malvaceae - "Hibiscus”. Myrtaceae - Eucalyptus sp.; Eugenia uniflora L.; Psidium guajava L. e Syzygium aromaticum (L.) Merr. \& L.M. Perry. Passifloraceae - Passiflora sp. Pedaliaceae - Harpagophytum procumbens. Piperaceae - "Kawa kawa". Plantaginaceae - Digitalis lanata Ehrh. e Digitalis purpurea var. valida. Poaceae - Cymbopogon citratus (DC.) Stapf. Rhamnaceae - Ziziphus joazeiro Mart. Rutaceae - "Limão". Salicaceae - Salix alba L. Schisandraceae - "Anis estrelado”. Solanaceae - Solanum paniculatum L. e Zingiberaceae - Zingiber officinale Roscoe. Uma média de 1,2 planta por estudante.

Podemos constatar que o principal interesse pela disciplina advém da possibilidade da descoberta de novos fármacos oriundos das plantas medicinais. Guerra e Nodari (2003) estimam que, apesar de apenas 8\% da flora brasileira ter sido cientificamente já avaliada na busca de novos princípios ativos, cerca de um quarto do faturamento da indústria farmacêutica é oriundo de medicamentos derivados de plantas. De fato, atualmente verifica-se crescente aumento nas pesquisas com plantas medicinais nos laboratórios de instituições de pesquisa e de empresas privadas, com o objetivo de isolar substâncias químicas com atividade farmacológica sendo que, apenas no Brasil, o mercado de fitoterápicos movimenta cerca de US\$ 160 milhões/ano (RÍOS e RECIO, 2005).

No entanto, precisamos ter cuidado quando tratarmos da indústria de medicamentos no que diz respeito à apropriação do conhecimento local no uso das plantas e da patenteação da biodiversidade, porém, esse debate é amplo e não entra nessa discussão, mas devido à sua extrema importância, merece ser abordado sempre que possível, quando considerarmos que o profissional Farmacêutico tem também um importante papel social (SILVA et al., 2017).

\section{4 REFORMULAÇÃO DA EMENTA}

Seguindo as considerações feitas pelos estudantes participantes dessa pesquisa e do que nos foi passado pela coordenação do curso de Farmácia - UFAL, desenvolvemos uma reformulação na disciplina. A ideia é que a mesma se torne mais atrativa aos estudantes e que não fuja ao propósito do estudo da botânica em seu contexto geral. Ressaltamos ainda que a nova ementa traga consigo uma interdisciplinaridade com todas as áreas da botânica, assim a disciplina poderá ser ministrada por vários professores do Setor de Botânica do ICBS - UFAL, cada um sendo o responsável pela sua área de especialização. Assim, sugerimos que a disciplina seja dividida em seis eixos centrais:

1. Etnobotânica - nesse eixo será abordado o histórico do uso de plantas pela humanidade, os conhecimentos tradicionais no uso das plantas na atualidade e a relação desse conhecimento com a construção da farmacopeia mundial; 
2. Sistemática de Algas - nesse eixo o objetivo principal será focar no(s) grupo(s) de algas usado(s) como medicamento;

3. Morfologia Vegetal - os estudos da morfologia do corpo da planta permitirão ao aluno o reconhecimento de todos os seus órgãos, reprodutivos e vegetativos;

4. Sistemática de Magnoliófitas - nesse eixo será ministrado como o uso dos caracteres morfológicos (vegetativos e reprodutivos) será utilizado para a identificação das plantas, evitando assim erros referentes ao seu uso como medicinal;

5. Anatomia Vegetal - através de conhecimentos em Anatomia Vegetal o aluno será capaz de reconhecer em níveis histológicos e celulares, o local de acúmulo do princípio ativo na planta;

6. Fisiologia e Bioquímica de Plantas - nesse eixo serão estudados conceitos de Fisiologia Vegetal e as principais rotas bioquímicas da produção de princípios ativos na planta.

Com essas mudanças pretende-se que a disciplina não só atinja seu objetivo central, o estudo da Botânica, como também se tornará mais atrativa para as/os discentes.

\section{CONSIDERAÇÕES FINAIS}

Mesmo não havendo a devolução de todos os questionários, o que inicialmente demonstrou desinteresse pela pesquisa, os dados mostram que os participantes, tanto os que ainda não cursaram quanto os que já a concluíram, em sua maioria, consideram importante a disciplina na grade do curso, porém com ressalvas para que o conteúdo englobe mais a área farmacêutica.

O interesse pela disciplina advém, principalmente, pela possibilidade de descoberta de novos fármacos.

Observou-se também um conhecimento considerável a respeito das plantas medicinais que vai desde a planta em si até sua forma de uso e indicações. Assim, podemos concluir que há uma resistência à disciplina pelo fato de ela não estar voltada à área do curso, porém observou-se um interesse por parte das/dos estudantes que consideraram importante sua permanência na grade curricular.

\section{REFERÊNCIAS}

CORRÊA, A. D.; VIEIRA, V.; LEITE, S. Q. M.; CORRÊA, F. P. Percepções dos discentes das graduações em Farmácia sobre o ensino de Homeopatia. Revista Práxis. 13: 91-103, 2015.

BARROS, S. M. S.; SIMÕES, K.; SILVA, M. P.; SOUZA, N.; FONSECA, S.; ROCHA, T. Levantamento de plantas medicinais com atividade antileishmania. Investigação. 15 (6), 2016.

BRITO, S. C. D.; RODRIGUES, W. Avaliação do marco regulatório na produção de medicamentos fitoterápicos no Brasil. Revista de Políticas Públicas. 9: 531-538, 2015.

CAVALCANTI-DANTAS, V. M.; MEDEIROS, K. L.; AZEVÊDO, V. T. K. B.; SANTANA, G. M.; PEREIRA, A. V.; GÓIS, M. B.; PEREIRA, M. S. V.; PEREIRA, J. V. Taninos: principal componente do extrato Piptadenia stipulacea (Benth) Ducke inibe o crescimento de cepas clínicas de Staphylococcus aureus de origem bovina.

Biotemas. 29: 109-114, 2016. 
FENALTI, J. M.; BACEGA, B.; MATA-SANTOS, T.; SANTOS, P. C.; SCAINI, C. J. Diversidade das plantas brasileiras com potencial anti-helmíntico. Vittalle - Revista de Ciências da Saúde. 28: 39-48, 2016.

FERREIRA, A. L. S.; BATISTA, C. A. S.; PASA, M. C. Levantamento etnobotânico nas diferentes realidades de ensino. Biodiversidade. 14: 60-73, 2015.

GUERRA, M. P.; NODARI, R. O. Biodiversidade: aspectos biológicos, geográficos, legais e éticos. In: Simões, C. M.; Schenkel, E. P.; Gosmann, G.; Mell, J. C. P.; Mentz, L. A.; Petrovick, P. R. (Org.). Farmacognosia: da planta ao medicamento. 5 ed. Porto Alegre/Florianópolis: Editora da UFRGS/ Editora da UFSC. p. 13-28, 2003.

LORENZI, H.; MATOS, F.J. Plantas Medicinais no Brasil: nativas e exóticas. Nova Odessa: Instituto Plantarum, 2002.

MATTA, A. P. L. F.; NASCIMENTO, G. E.; MATTA, S. L. P.; LEITE, J. P. V. Efeitos dos extratos alcoólicos de Pfaffia glomerata (Spreng) Pedersen e Anemopaegma glaugum (Mart) DC sobre rins de camundongos adultos. Multiverso. 1: 161-170, 2016.

NÓBREGA, J. S.; SILVA, F. A.; BARROSO, R. F.; CRISPIM, D. L.; OLIVEIRA, C. J. A.;. Avaliação do conhecimento etnobotânico e popular sobre o uso de plantas medicinais junto a alunos de graduação. Revista Brasileira de Gestão Ambiental. 1: 7-13, 2017.

NOGUEIRA, A. C. O.; SABINO, C. V. S.; CHAVES, A. C. A Botânica como diretriz nos cursos de fitoterapia para profissionais da saúde. 64 Congresso Nacional de Botânica. Belo Horizonte-MG, Brasil, 2013. p. 1-2.

RÍOS, J. L.; RECIO, M. C. Medicinal plants and antimicrobial activity. Journal of Ethnopharmacology. 100: $80-84,2005$.

SANTOS, K. A. S.; SILVA, E. S.; OLIVEIRA, M. R.; BORSATO, A. V. (2016). Rendimento do óleo essencial de folhas de Vitex agnus castus L. em diferentes períodos de coleta. Cadernos de Agroecologia. 11: 1-5.

SILVA, L. W. F. Plantas medicinais usadas pela população do município de Sertãozinho - Paraíba: um recurso didático no ensino médio - 56p. (Monografia Licenciatura em Ciências Biológicas / EAD) - Universidade Federal da Paraíba, João Pessoa - PB, 2013.

SILVA, M. J. S. O papel social do farmacêutico no capitalismo. Lutas Sociais. 19: 39-52, 2015

SILVA, P. F.; ANDRADE, J. R.; LEITE, F. R. P. Farmacêutico: breve trajetória histórica de sua profissão e formação acadêmica. Revista Latino-Americana de Educação, Cultura e Saúde. 1: 19-26, 2017.

SOUZA, V. A.; LIMA, D. C. S.; VALE, C. R. Avaliação do conhecimento etnobotânico de plantas medicinais pelos alunos de ensino médio da cidade de Inhumas, Goiás. Revista Eletrônica de Educação da Faculdade Araguaia. 8: 13-30, 2015.

TROPICOS-HOME. - http://www.tropicos.org. Acessado em 9 setembro/2016.

VAN DEN BERG, M. E Plantas medicinais da Amazônia: contribuição ao seu conhecimento sistemático. Belém: Conselho Nacional de Desenvolvimento Científico e Tecnológico - Programa Trópico Úmido - Museu Paraense Emílio Goeldi, 1987. 